\title{
A INCIDÊNCIA DA
}

\section{VARIAÇÃO DENOMINATIVA}

NA COMPREENSÃO DO CONCEITO

ESPECIALIZADO NA ÁREA DA

LEXICOGRAFIA: UM ESTUDO

COM UNIVERSITÁRIOS

\section{BRASILEIROS}

LA INCIDENCIA DE LA VARIACIÓN DENOMINATIVA EN LA COMPRENSIÓN DEL CONCEPTO ESPECIALIZADO EN EL ÁREA DE LA LEXICOGRAFÍA: UN ESTUDIO CON ESTUDIANTES UNIVERSITARIOS BRASILEÑOS

THE INCIDENCE OF DENOMINATIVE VARIATION IN THE COMPREHENSION OF THE SPECIALIZED CONCEPT IN THE AREA OF LEXICOGRAPHY: A RESEARCH WITH BRAZILIAN UNIVERSITY STUDENTS

\footnotetext{
* Doutora em Linguística pela Universidade Estadual Paulista (UNesp) e doutora em Traducción y Ciencias del lenguaje (UPF, Barcelona). Atualmente é Pós-Doutoranda na Universidade de São Paulo (USP). E-mail: lucimara.costa@hotmail.com.

** Docente e investigadora em Linguística Aplicada. Atualmente é coordenadora do Departamento de Traduça e Interpretaça da Pontificia Universidad Católica de Valparaíso (Chile) e Coordenadora do projeto de la Antena de neologíadeValparaíso(NEOVALPO).E-mail:sabela.fernandez@pucr.cl.

*** Doutora em Linguística pela Universidade Estadual de Campinas e possui pós-doutorado em Linguística pela Universidade de São Paulo. Atualmente é docente do Departamento de Letras da Universidade Federal de Mato Grosso doSul (UFMS). E-mail: vspanghero@gmail.com.
} 
RESUMO: Neste trabalho, embasados nos pressupostos teóricos das teorias cognitivas da Terminologia, tivemos por objetivo analisar a incidência da variação denominativa para a compreensão do conceito especializado no âmbito da Lexicografia. Para isso realizamos um estudo experimental com estudantes de Letras de uma universidade brasileira. Aplicamos uma prova de compreensão leitora a partir de textos de Lexicografia que apresentavam conceitos especializados mediante variação. Os resultados mostraram que a variação influencia cognitivamente no processo de compreensão textual e, portanto, possui uma incidência para o leitor na forma como este compreende e constrói o conceito.

PALAVRAS-CHAVE: Variação denominativa. Compreensão conceitual. Lexicografia.

RESUMEN: En este trabajo, basado en los supuestos teóricos de las teorías cognitivas de la Terminología, tuvimos como objetivo analizar la incidencia de la variación denominativa para la comprensión del concepto especializado en el contexto de la Lexicografía. Para esto, realizamos un estudio experimental con estudiantes de Letras de una universidad brasileña. Aplicamos una prueba de comprensión lectora a partir de textos de Lexicografía que presentaba conceptos especializados mediante la variación. Los resultados mostraron que la variación influye cognitivamente en el proceso de comprensión textual y, por lo tanto, tiene un impacto para el lector en la forma como él entiende y construye el concepto.

PALABRAS CLAVE: Variación denominativa. Comprensión lectora. Lexicografía.

ABSTRACT: Based on the theoretical assumptions of the cognitive theories of Terminology, this work aimed to analyze the incidence of denominative variation in the understanding of the specialized concept of Lexicography. In order to achieve this goal, we conducted an experimental research with Brazilian university students of Letras course. We applied a test of reading comprehension from Lexicography texts that presented specialized concepts based on variation. The results showed that variation influences cognitively in the process of textual comprehension and, consequently, has an impact on how the reader understands and constructs the concept.

KEYWORDS: Denominative variation. Understanding of the specialized concept. Lexicography.

\section{INTRODUÇÃO}

A variação denominativa (utilização de denominações distintas para representar um mesmo conceito) é um fenômeno bastante estudado pelas modernas teorias da Terminologia, como a Teoria Comunicativa da Terminologia (CABRÉ, 1999), a Teoria Sociocognitiva (TEMMERMAN, 2000) e a Terminologia embasada em marcos (FABER et al., 2006, 2012).

Seguindo uma ótica descritivista e cognitivista, muitos dos trabalhos derivados dessas teorias têm estudado a variação levando em conta fatores dialetais e funcionais, tais como: o registro (FAULSTICH, 1997, 1998, 2000); a evolução do conhecimento (TEMMERMAN, 2000); o nível de especialização (FREIXA, 2002; CIAPÚSCIO, 2003); o status socioprofissional (BERTACCINI; MATTEUCI, 2005) e o canal (SEGHEZZI, 2011), mas também fatores cognitivos (ROGERS, 2004; BOWKER; HAWKINS, 2006; FERNÁNDEZ-SILVA et al., 2011; TERCEDOR, 2011; PECMAN, 2014; FERNÁNDEZ-SILVA, 2016; COSTA; FERNÁNDEZSILVA 2018).

Sob uma perspectiva cognitiva, a variação pode estar relacionada à dinamicidade do processo de categorização e construção do conhecimento especializado, podendo este processo, entre outros fatores, estar direcionado por uma motivação cognitiva (FERNÁNDEZ-SILVA, 2011; TERCEDOR, 2011; PECMAN, 2014), que se deve à maneira particular de compreender (e denominar) o conceito por parte de cada autor. Outros autores têm sugerido que a variação tem uma função cognitiva (FERNÁNDEZ-SILVA, 2016; COSTA; FERNÁNDEZ-SILVA, 2018), pois distintas variantes em um mesmo texto podem enfatizar aspectos distintos do conteúdo conceitual e, portanto, proporcionar uma visão enriquecida deste, facilitando a compreensão do leitor.

Em investigações anteriores, Fernández-Silva e Becerra (2015), Fernández-Silva, (2016) e Costa e Fernández-Silva (2018) estudaram a função cognitiva em corpora textuais de distintas áreas, tendo como hipótese o fato de que quanto maior a informação semântica proporcionada pelas variantes, maior a função cognitiva representada por elas. Entretanto, não existem, até 
o momento, investigações em que se tenha estudado, empiricamente, a incidência da variação denominativa para a compreensão dos conceitos especializados por parte dos receptores dos textos.

Sendo assim, neste trabalho, consideramos a hipótese de que a variação denominativa representa uma incidência positiva na forma como o leitor compreende e constrói o conceito especializado, uma vez que a utilização de denominações distintas pode auxiliar na compreensão do conceito, seja oferecendo informações adicionais ao conceito e que não podem ser depreendidas no termo de referência ${ }^{1}$, seja reforçando características já apresentadas no primeiro termo.

Nesse sentido, nesta investigação tivemos por objetivo analisar a incidência da variação denominativa na compreensão do conceito especializado em textos do âmbito da Lexicografia, procurando comprovar ou refutar a hipótese acima mencionada, bem como comprovar como a presença dessas variações podem interferir no processo de interpretação textual, por parte dos estudantes.

Para isso, consideramos como metodologia de trabalho a aplicação de uma prova de compreensão leitora, constituída por um questionário com perguntas interpretativas a respeito dos conceitos especializados no âmbito da Lexicografia, tendo como participantes estudantes universitários do curso de Letras de uma universidade pública do Brasil.

Para uma melhor compreensão desta proposta, após essa introdução, apresentamos o marco teórico no qual se fundamenta a investigação, a metodologia empregada e as análises e resultados. Posteriormente, passamos às conclusões e referências bibliográficas utilizadas.

\section{MARCO TEÓRICO}

Nesta investigação, nos embasamos nos pressupostos das teorias terminológicas de corte cognitivista procurando explicar a relação entre a variação denominativa e os estudos da compreensão do discurso escrito, bem como a influência dessa variação na compreensão do conceito especializado.

\subsection{TEORIAS COGNITIVAS E A VARIAÇÃO TERMINOLÓGICA}

A relação entre linguagem e pensamento é algo amplamente aceito, da mesma forma, também é consensual, por parte dos linguistas cognitivos, o fato de que a linguagem se fundamenta na interação com o mundo, por meio de nossas vivências e experiências físicas, corporais e cognitivas. Nesse sentido, como destaca Ibarrete- Antuñano e Valenzuela (2012, p. 7), uma das premissas fundamentais da Linguística Cognitiva é a de que a linguagem é uma capacidade integrada na cognição geral. Linguagem, significado e conhecimento estão perfeitamente interconectados, atuando a linguagem como entrada ao sistema conceitual, mas também como o meio pelo qual esse sistema conceitual é exteriorizado e verbalizado (FÉREZ, 2012, p. 190).

Como ressaltam Fernández-Silva et al. (2012, p. 197), a linguagem é um instrumento por meio do qual se delimitam e delineiam os conceitos gerais, mas também científicos através da interação entre especialistas, seja oralmente ou por meio de textos escritos. Sendo assim, ao se nomear uma nova realidade, essa denominação funciona como uma porta de entrada que possibilita o acesso à compreensão do conceito e, por isso mesmo, reforça-se a ideia de que existe um forte vínculo entre nome e conceito. Relação esta que pode, de acordo com as autoras, ser descrita e explicada por uma motivação cognitiva. Argumento defendido, também, pela Linguística Cognitiva.

Entre os pressupostos da Linguística Cognitiva, uma das principais ideias a ser destacada, como aponta Geeraerts (2006), é o fato de que para se alcançar um nível adequado de compreensão, os conceitos não devem ser descritos apenas por meio de uma

\footnotetext{
${ }^{1}$ Considera-se termo de referência a primeira denominação apresentada no fragmento textual, sendo os demais termos a ele relacionados considerados como suas variantes denominativas.
} 
definição abstrata, mas sim, levando em conta todos os aspectos sobre os quais se fala nessa definição, o que poderia estar expresso, inclusive, no próprio termo cujo conceito esperamos destacar.

Isso se justifica, como diz o próprio autor, pelo fato de que o significado não é apenas um reflexo objetivo do mundo exterior, e sim uma realidade dinâmica e flexível, uma vez que o mundo se constrói de uma maneira particular e o significado se molda a este, estando o mesmo em constante mudança (GEERAERTS, 2006, p. 4). Em outras palavras, podemos dizer que a construção e categorização do conceito é um processo dinâmico no qual influem diversos fatores. Assim, a linguagem não é um módulo separado e independente da mente, pois nosso conhecimento e representação mental se constroem com base no uso e em nossa experiência como seres humanos. É essa experiência que orienta nossa construção de mundo, ou seja, nossa compreensão.

Atuando como um mecanismo linguístico, mas também social e cognitivo, a variação terminológica, em especial a denominativa, é um passo importante na forma como se relaciona linguagem e pensamento, denominação e conceito. Conforme destaca Tercedor (2011, p. 182), a variação é também um reflexo dos processos dinâmicos de categorização e estruturação do conhecimento especializado e, sendo assim, essa variação tem uma motivação cognitiva, que se verifica na forma como o autor transmite as informações em um texto, mas também possui uma consequência ou incidência, que se refere à compreensão do conceito expresso por essas variantes por parte dos receptores, interferindo na maneira como os textos são interpretados.

Isso ocorre porque, segundo Fernández-Silva (2016), a variação denominativa nos textos proporciona informações intra e intercategoriais, uma vez que sua utilização propicia ao leitor ter acesso tanto ao conteúdo conceitual, apresentado pela própria variante, como também estabelecer relações com outros conceitos apresentados no texto, o que lhe permite uma compreensão mais eficaz. Como ressalta Pecman (2014, p. 10), a utilização de diferentes variantes para um mesmo conceito permite ressaltar diferentes aspectos de seu conteúdo e contribui “[...] para o processo contínuo de construção do conhecimento".

Nesse sentido, as propostas teóricas de corte cognitivo, como a Teoria Sociocognitiva da Terminologia (TEMMERMAN, 2000), a Teoria Comunicativa da Terminologia (CABRÉ, 1999, 2008) ou a Teoria embasada em marcos (FABER et al., 2006, 2012) têm integrado modelos semânticos procedentes das ciências cognitivas em suas explicações sobre a formação e estruturação dos conceitos especializados, bem como as características dos sistemas conceituais e sua denominação por meios linguísticos.

Um dos pressupostos principais da Teoria Sociocognitiva da Terminologia (TEMMERMAN, 2000) consiste, justamente, em sua explicação sobre a dinamicidade dos processos de categorização e da variedade de cenários cognitivos e comunicativos que permeiam a comunicação especializada. Para a autora, o processo de construção e categorização do conhecimento não são estáticos, assim, as características de um conceito são funcionais e interativas e, por esse motivo, podem sofrer variações, considerando os diversos fatores cognitivos e comunicativos envolvidos no processo de construção do conhecimento especializado e sua comunicação por meio da linguagem.

Por sua vez, Cabré (1999), com a Teoria Comunicativa da Terminologia, nos permite contemplar a variação linguística em toda sua dimensionalidade, possibilitando-nos o acesso a um modelo variacionista e textual que permite considerar e descrever a variação em todos os níveis linguísticos, discursivos e comunicativos.

Diversos estudos embasados nesta teoria têm explorado a dimensão cognitiva da variação e seus fatores comunicativos e linguísticos. Como exemplos destes podemos citar os estudos de Freixa (2002), que estabelece uma tipologia de causas da variação, diferenciando-as em causas dialetais, funcionais, discursivas, interlinguísticas e cognitivas, e de Fernández-Silva (2011), que desenvolve uma tipologia de fatores cognitivos de variação, distinguindo entre eles os fatores sistêmicos, isto é, relacionados à flexibilidade dos conceitos e à multidimensionalidade dos sistemas conceituais, bem como os fatores contextuais, que se relacionam com as diferenças de conceitualização entre grupos de usuários ou em um mesmo usuário, em diferentes situações ou no interior de um mesmo texto.

Finalmente, a Terminologia embasada em marcos (FABER et al., 2006, 2012) apresenta uma proposta de representação conceitual embasada na semântica de marcos (FILLMORE, 1985). De acordo com essa teoria, para caracterizar de maneira apropriada o significado dos elementos linguísticos deve-se, em primeiro lugar, conhecer as estruturas conceituais subjacentes, nas quais se 
embasam esses elementos e que, por sua vez, proporcionam um contexto mínimo e imprescindível para sua compreensão. A Terminologia embasada em marcos procura refletir esse caráter multidimensional, flexível e situado da estruturação conceitual na elaboração de seus recursos terminológicos e lexicográficos, o que inclui, também, a variação conceitual e denominativa.

Estas são algumas das teorias terminológicas de corte cognitivas que mais têm se destacado a respeito dos estudos da variação. Entretanto, vêm se reiterando, nos últimos anos, a influência que a variação denominativa desempenha na compreensão, embora sejam poucos, ainda, os estudos empíricos que tenham abordado, especificamente, essa relação entre variação e compreensão conceitual, como discorreremos melhor na próxima seção.

\subsection{COMPREENSÃO DO DISCURSO ESCRITO E OS ESTUDOS SOBRE A VARIAÇÃO}

De acordo com Parodi (2014), o desenvolvimento tecnológico, ocorrido no século XXI, proporcionou um grande avanço no estudo da relação discursiva entre escritor e leitor, ocasionando uma melhoria considerável a respeito do processo de compreensão do discurso escrito. Entretanto, persistem ainda muitas dificuldades e problemas envolvidos nesse processo, o que suscita muitas dúvidas sobre como funciona o fenômeno da compreensão de textos escritos e, também, sobre a relação entre texto/escritor e leitor.

Dentre estes questionamentos apresenta-se o papel das variantes denominativas, sendo estas um recurso linguístico, mas também cognitivo, apresentado nos textos. Entretanto, embora existam muitos estudos sobre a correferência e marcadores discursivos como mecanismos ou recursos para a compreensão, faz-se necessário mais estudos sobre o papel das variantes denominativas na compreensão textual e a incidência dessa variação para o leitor.

Entre alguns dos trabalhos desenvolvidos nos últimos anos sobre essa temática, destacamos os estudos de Fernández-Silva e Becerra (2015) e Fernández-Silva (2016), que constatam a possibilidade de se medir a distância semântica entre as variantes de um texto, defendendo que quanto maior a distância e informação semântica entre o termo de referência e sua variante, maior sua função cognitiva.

Um estudo semelhante foi realizado por Costa e Fernández-Silva (2018), ao analisar a função cognitiva da variação no âmbito da Lexicografia e as informações aportadas pelas variantes, utilizando como parâmetro de análise a classificação de Kageura (2002), a fim de estabelecer os padrões conceituais e as relações intratermo das variantes, bem como a distância semântica entre elas, utilizando a classificação de Fernández-Silva (2016).

Convém destacar também o estudo de Suárez (2016), no qual realiza uma investigação embasada em análise de corpus, discorrendo sobre a influência da variação denominativa explícita na compreensão do conceito, utilizando, para isso, a técnica de movimento ocular (eye-tracking). Nesse trabalho, a autora analisou o papel dos marcadores discursivos na compreensão de textos em estudantes de Engenharia Biomédica e tradutores em formação. Segundo Suárez (2016), alguns marcadores discursivos dificultam a compreensão do texto e fazem com que a compreensão seja mais lenta por parte dos estudantes.

Entretanto, destaca-se que, ainda que os estudos terminológicos sobre a variação tenham avançado muito nos últimos anos, prevalece uma maior atenção aos estudos da variação como objeto, produto ou resultado (variação e sua representação), e pouco enfoque no seu processo ou incidência para o receptor na compreensão e construção do conhecimento especializado. O mesmo pode se dizer a respeito dos processos cognitivos que ocorrem durante a leitura e compreensão de um texto ou conceito e a aquisição do conhecimento especializado.

Convém destacar que, além dos elementos cognitivos como memória, atenção e concentração, alguns elementos linguísticos também influenciam na compreensão do conceito e, por conseguinte, na construção do conhecimento, o que ocorre, por exemplo, com o uso de variantes denominativas em um texto especializado. Isto acontece porque a utilização de diferentes variantes para um mesmo conceito permite ressaltar diferentes aspectos do seu conteúdo e, sendo assim, o emprego de variantes 
denominativas. Muito mais que um recurso estilístico, desempenha também uma função cognitiva, que se manifesta na superfície textual e que faz com que o leitor conecte e organize as diversas informações para alcançar uma construção efetiva do conceito, apresentando, portanto, uma incidência positiva ao leitor.

\section{METODOLOGIA}

Nesta seção descrevemos os procedimentos metodológicos utilizados neste trabalho para: a) o desenho dos experimentos de análise e avaliação (questionários); b) validação e pilotagem; c) seleção dos participantes; d) aplicação dos questionários; e) análise dos dados.

\section{a) Desenho dos experimentos (questionários)}

Utilizamos, nesta pesquisa, como instrumento de análise e avaliação da compreensão leitora dos estudantes, dois modelos de questionários ou provas de interpretação. Cada questionário foi confeccionado com dez fragmentos de textos (dez a vinte linhas) que, no corpus original, apresentam variação denominativa explícita, ou seja, claramente marcada por meio de marcadores discursivos de equivalência ou sinonímia.

Os fragmentos textuais apresentados foram selecionados de textos especializados da área de Lexicografia, retirados de um corpus constituído por quinhentos textos especializados, escritos em português brasileiro em um recorte temporal de 1980 a 2015 . Este corpus (Corpus_DLB) foi construído para a tese de doutorado de Costa (2015) e ampliado para o pós-doutorado da mesma autora, realizado durante o ano de 2016/2017. Selecionamos textos de baixo e médio nível de complexidade, como artigos, resumos e resenhas direcionados a estudantes, professores e especialistas da área do léxico, e publicados em manuais e revistas especializadas.

Para o desenho desses questionários consideramos um modelo de quadrado latino, que consiste em gerar duas listas, nas quais cada texto experimental é apresentado de maneira alternada, com presença e ausência de variantes. Por essa razão, cada texto possui duas formas: o original, com variantes denominativas, e sua reformulação, sem variantes, que aparecem intercaladas entre o modelo A e o modelo B.

Nos dois modelos de questionários foram considerados os mesmos textos e perguntas. A diferença é que em um modelo o texto se apresentava em sua versão original, com o termo de referência e sua respectiva variante ou variantes denominativas, e no outro modelo uma versão modificada do fragmento em que se omitia(m) a(s) variante(s) denominativa(s).

Para avaliar a compreensão, cada texto vinha acompanhado de uma questão, cada uma com cinco afirmações, na qual se solicitava ao estudante que assinalasse as corretas. Cada afirmação correta apresentava características distintas do conceito que podiam estar representadas no termo de referência ou nas variantes denominativas. As alternativas incorretas apontavam também características conceituais, mas que remetiam a outros conceitos que não o solicitado, como se pode verificar no exemplo abaixo ${ }^{2}$, em que se discute o conceito de "dicionário de língua", representado, também, por sua variante "dicionário de usos".

\section{Exemplo - Texto 1:}

Partindo-se do princípio de que um dicionário de língua deve ser avaliado a partir de sua concepção teórica, entendendo-se esta como uma teoria gramatical, uma das primeiras dificuldades enfrentadas pelo dicionarista é como organizar verbetes de palavras gramaticais. Entenda-se dicionário de língua como aquele que dá informações sistemáticas sobre a estrutura e o funcionamento da língua. Assim também pode ser chamado de dicionário de usos. Aliás, são eles que mostram com mais clareza a opção teórica do dicionarista. As dificuldades, que se relacionam principalmente com tomada de posição, vão desde a rotulação de classes e

${ }^{2}$ Os dois modelos de questionários completos serão apresentados nos anexos. 
subclasses até a organização de matrizes estruturais, naturalmente ligadas a uma complementação possível (BORBA, 2007).

\section{Exemplo - Questionário - pergunta 1}

1. Com base no conceito de dicionário de língua expresso no trecho anterior, quais das seguintes afirmações são corretas?

a) ( ) obra que orienta sobre a utilização de uma determinada unidade lexical.

b) ( ) produto lexicográfico que se estrutura tendo por base palavras da linguagem especializada.

c) ( ) obra lexicográfica cujo objetivo é esclarecer dúvidas a respeito do significado e apresentar informações sobre formação, sinonímia, contexto, entre outros aspectos da palavra-entrada.

d) ( ) produto que apresenta uma organização semasiológica reduzida e se destina ao público infantil ou ambiente escolar.

e) ( ) repertório lexicográfico que se organiza por campos semânticos e tem como objetivo orientar aprendizes de uma segunda língua.

Para evitar que o estudante estabelecesse um padrão de resposta, cinco das questões apresentavam três alternativas corretas e cinco continham apenas duas afirmações verdadeiras. Com esse questionário, objetivamos avaliar o nível de compreensão conceitual do estudante e de que forma a presença ou ausência de variantes no texto influencia na compreensão final do conceito. Se a compreensão é mais efetiva em textos com variação e se o uso de variantes apresenta informações complementares a essa compreensão e que não podem ser depreendidas pelo termo de referência.

\section{b) Validação e pilotagem}

Depois de elaborados, os questionários passaram por uma etapa de validação e pilotagem. Para essa validação selecionamos três professores universitários especialistas da área da Compreensão do Discurso Escrito e três da área do Léxico, para os quais foram enviados as duas versões dos questionários acompanhados de um instrumento de avaliação, que consistia em analisar a qualidade dos questionários (textos e perguntas), observando os seguintes critérios:

a) se o sentido do texto fonte era mantido em sua versão reformulada;

b) se o conteúdo de ambos os textos era compreensível para o nível dos estudantes;

c) se o léxico apresentado nos textos era adequado ao nível escolar dos estudantes;

d) se as perguntas formuladas em cada texto enfocavam o conceito apresentado nos fragmentos textuais;

e) se as perguntas formuladas em cada um dos textos orientavam quanto ao conceito que se queria destacar;

f) se a pergunta era clara; e,

g) se as alternativas apresentadas em cada pergunta eram pertinentes.

Depois de validados esses instrumentos, realizamos as correções e alterações solicitadas pelos especialistas que consistiram basicamente em:

(i) deixar mais claro o conceito especializado que se pretende destacar no enunciado da questão, utilizando para isso o recurso de letra em negrito, como por exemplo: "Das seguintes afirmações as que maior reforçam o conceito de nomenclatura veiculado no trecho anterior, são:";

(ii) traduzir para o português as variantes apresentadas em outras línguas, como é o caso da variante front matter na questão número 10. Exemplo: "Por fim, o front matter ${ }^{\star}$ tem como funções básicas apresentar os objetivos que o dicionário pretende cumprir e funcionar como um manual de instruções de uso do mesmo [...] (FARIAS, 2008). * matéria frontal;

(iii) considerar sempre a mesma estrutura para todas as alternativas, partindo do substantivo e de uma paráfrase explicativa sobre ele, como apresentamos no exemplo a seguir: 
a) ( ) disciplina que se enfoca em unidades do léxico geral com o objetivo de criar bancos de dados e dicionários de língua.

b) ( ) ramo da Lexicografia que se volta para a criação de dicionários especializados.

c) ( ) técnica que tem por objetivo a confecção de dicionários direcionados ao público infantil.

d) ( ) ciência que se ocupa do estudo de unidades especializadas com o objetivo de produzir glossários e dicionários de língua geral.

e) ( ) disciplina ou ciência que se preocupa da análise de unidades especializadas de um âmbito com o objetivo de produzir bancos de dados e obras lexicográficas ou terminológicas.

Terminadas as correções, passamos à fase de pilotagem, que consistiu na aplicação dos questionários a um grupo restrito de estudantes com o mesmo perfil dos participantes que seriam avaliados posteriormente. Assim, em uma sala de 44 estudantes universitários do primeiro ano de Letras de uma universidade federal brasileira, selecionamos, de forma aleatória, oito participantes para realizar essa pilotagem; quatro alunos para fazer o questionário A e os outros quatro restantes, o questionário B.

Posteriormente, analisamos os questionários observando se os estudantes conseguiram respondê-los, se os textos e enunciados estavam claros e se não tiveram nenhuma dúvida ao responder às perguntas.

A pilotagem nos revelou que os alunos não tiveram problemas ao interpretar os enunciados, uma vez que responderam, coerentemente, o solicitado, e preencheram totalmente os questionários. Por isso não realizamos nenhuma alteração antes de aplicá-los ao restante do grupo, na fase seguinte.

\section{d) Seleção dos participantes}

Para esta investigação, consideramos como participantes estudantes de Letras do primeiro ano de uma universidade federal do Brasil. Tendo em vista as exigências e implicações do comitê de ética para pesquisas que envolvam outros participantes, solicitouse à professora titular da disciplina de Lexicografia uma autorização para a aplicação do questionário com sua turma. Ressaltamos que os estudantes não foram avisados previamente, para que pudéssemos simular uma situação de exame real, mas que eles foram avisados e consultados antes de que o questionário fosse aplicado, estando estes livres para saírem da sala, caso não quisessem participar. Como não era uma situação que envolvesse atribuição de notas à disciplina ou qualquer outro tipo de avaliação que pudesse prejudicar os estudantes em sala, todos aceitaram participar e não houve nenhum problema ou reclamação por parte dos estudantes.

Os questionários foram aplicados para 36 estudantes, selecionados entre a quantidade de 44 alunos na totalidade e descartados os oito estudantes com os quais realizamos o teste de pilotagem. Para a seleção dos participantes consideramos critérios como: a) estudantes com pouco ou nenhum conhecimento sobre Lexicografia de forma que os conhecimentos prévios não pudessem interferir ou direcionar na compreensão dos conceitos; b) uma turma numerosa, a fim de que pudéssemos realizar as etapas de pilotagem e aplicação dos questionários com estudantes dessa mesma série.

\section{e) Aplicação dos questionários}

Terminada a etapa de avaliação, validação e pilotagem dos questionários passamos à fase de aplicação destes. Nessa etapa, dos 36 estudantes selecionados, dezoito fizeram o modelo A do questionário e dezoito fizeram o modelo B.

Os questionários foram impressos e a seleção dos estudantes foi feita de forma aleatória, tomando o cuidado de distribuir as provas de modo que cada aluno tivesse acesso a apenas uma versão do texto, ou seja, ou leram o texto em sua versão original com variantes ou em sua versão modificada em que as variantes foram suprimidas. 
Os estudantes selecionados foram retirados da sala e levados a uma outra sala para realizarem a avaliação, sem interferências ou ruídos externos e tiveram uma hora para o preenchimento do questionário, embora todos tenham terminado a avaliação antes do horário limite.

\section{ANÁLISE DOS DADOS}

Depois de aplicados os questionários, procedemos à análise quantitativa e qualitativa dos dados. Para essa análise, consideramos aspectos como: (a) o nível de compreensão conceitual (efetiva, parcial ou insuficiente) em textos com e sem variantes, tendo como base uma escala de pontuação que vai de 0.0 a 1.0.; e (b) a porcentagem do nível de compreensão obtida em cada pergunta do questionário.

Para obter essa pontuação, utilizamos os seguintes critérios de avaliação: 0.33 para um acerto de uma questão com três alternativas corretas; 0.5 para um acerto de uma questão com duas alternativas corretas; 0.66 quando o estudante tiver dois acertos de uma questão com três alternativas corretas; 0.75 quando o estudante assinalar outras opções além das alternativas corretas e 1.0 para as questões inteiramente corretas.

Assim, a relação entre nível de compreensão e pontuação estabeleceu-se da seguinte forma:

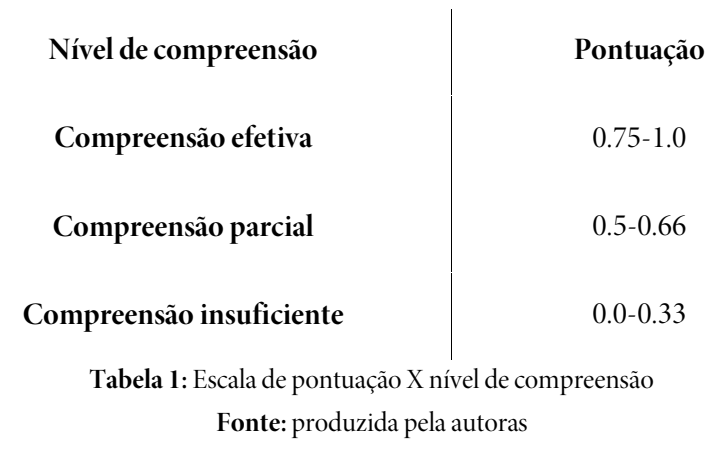

Consideramos que a compreensão foi totalmente efetiva quando houve um acerto total das questões, alcançando 1.0, e também nos casos de pontuação 0.75 , que ocorreu nos textos em que os estudantes acertaram todas as alternativas corretas das questões e assinalaram alternativas extras, o que pode significar que ele considerou traços distintos do conteúdo conceitual.

Se essa pontuação foi alcançada nos textos com variantes (CV), entendemos que a variação teve uma incidência positiva, ou seja, auxiliou na compreensão do conceito apresentando características adicionais ao termo de referência. Se essa pontuação ocorreu nos textos sem variantes (SV), consideramos que a variação não interferiu na compreensão.

A compreensão foi parcialmente efetiva nos casos dos textos com pontuação 0.66 e 0.5 , ou seja, quando os estudantes acertaram metade da questão. Se esse valor foi alcançado nos textos sem variantes, compreendemos que faltou ao estudante um traço adicional para a construção do conceito e que este estaria veiculado na variante suprimida. No entanto, se isso ocorreu nos textos com variantes, entendemos que a variante não aportou nenhuma informação que favorecesse a compreensão e, portanto, não teve consequência cognitiva para o leitor.

Já no caso dos textos em que se apresentavam variantes e que foi maior o número de erros totais (0.0) e pontuação 0.33 , entendemos que, de alguma forma, a variação prejudicou a compreensão e, sendo assim, a incidência foi negativa e a compreensão foi insuficiente. Passamos às análises e aos resultados. 


\section{RESULTADOS}

Nossa análise foi dividida em duas partes: em primeiro lugar, verificamos o nível de compreensão da totalidade do questionário dos textos com e sem variantes e, em segundo lugar, analisamos a porcentagem do nível de compreensão obtido em cada pergunta.

\subsection{NÍVEL DE COMPREENSÃO CONCEITUAL EM TEXTOS COM E SEM VARIANTES E TEXTOS}

Na primeira parte, nosso objetivo foi verificar se houve diferença no nível de compreensão dos textos com e sem variantes, considerando as 180 perguntas (dez perguntas e dezoito questionários) disponibilizadas em cada questionário. Assim:

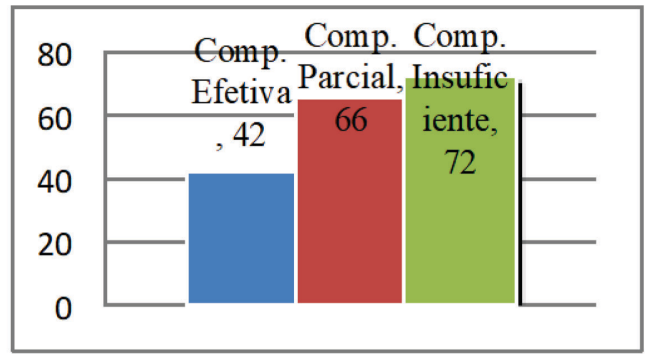

Gráfico 1: Nível de compreensão em textos com variantes Fonte: produzido pela autoras

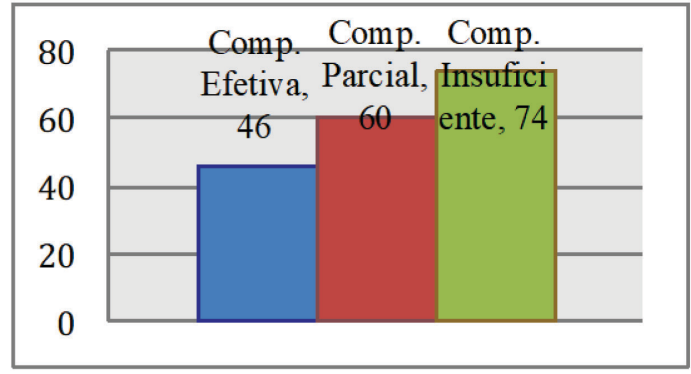

Gráfico 2: Nível de compreensão em textos sem variantes Fonte: produzido pela autoras

Como se observa nos dados acima, constata-se um certo equilíbrio no nível de compreensão conceitual entre os textos com e sem variantes. Verificou-se que foi maior o nível de compreensão efetiva nos textos sem variação, o que sugere que, ao menos quantitativamente, a variação não influenciava cognitivamente na compreensão do conceito, de forma que a omissão das variantes não impediu que os estudantes compreendessem todas as informações conceituais.

Quanto ao nível de compreensão parcial, observou-se que foi maior o nível em textos com variantes, provando que o uso de variantes possuía uma influência cognitiva sobre a compreensão dos conceitos, entretanto, as informações aportadas pelas variantes, ou mesmo pelas informações disponibilizadas na superfície textual, não foram suficientes para que os estudantes compreendessem totalmente o conceito solicitado.

Em relação ao nível de compreensão insuficiente, constatamos que este foi maior tanto nos textos que apresentavam variantes, quanto nos textos em que essas variantes foram omitidas. Entretanto, foi maior a quantidade de estudantes que alcançaram essa pontuação nos textos sem variantes.

Analisando os dados apresentados, pudemos comprovar que, ainda que a variação apresente uma influência cognitiva sobre a compreensão, os resultados não nos permitiram delimitar claramente a incidência da variação, uma vez que foi ínfima a diferença nos textos com e sem variantes, o que pode se justificar pela influência de outros fatores que interferiram nesse processo, como por 
exemplo, o alto nível de complexidade para o baixo nível de conhecimento sobre o assunto por parte dos estudantes, relacionado à falta de prática de se trabalhar com textos especializados em sala de aula, principalmente durante o ensino médio e anos iniciais da universidade.

\subsection{NÍVEL DE COMPREENSÃO CONCEITUAL OBTIDO POR PERGUNTA}

Nesta seção, procuramos analisar a porcentagem obtida em cada pergunta em relação ao nível de compreensão conceitual. Para isso, analisamos o conceito solicitado em cada pergunta e o nível de compreensão obtido nos textos com e sem variantes, levando em consideração as afirmativas apresentadas em cada questão e as alternativas corretas.

\begin{tabular}{|c|c|c|c|c|c|c|}
\hline \multirow{2}{*}{$\begin{array}{c}\text { Textos/questões } \\
\text { Conceito }\end{array}$} & \multicolumn{3}{|c|}{ Textos com variantes } & \multicolumn{3}{|c|}{ Textos sem variantes } \\
\hline & $\begin{array}{l}\text { Comp. } \\
\text { efetiva }\end{array}$ & $\begin{array}{l}\text { Comp. } \\
\text { parcial }\end{array}$ & $\begin{array}{c}\text { Comp. } \\
\text { Insuficiente }\end{array}$ & $\begin{array}{l}\text { Comp. } \\
\text { efetiva }\end{array}$ & $\begin{array}{l}\text { Comp. } \\
\text { parcial }\end{array}$ & $\begin{array}{c}\text { Comp. } \\
\text { Insuficiente }\end{array}$ \\
\hline 1. dicionário de língua & $47 \%$ & $42 \%$ & $11 \%$ & $33 \%$ & $50 \%$ & $17 \%$ \\
\hline 2. dicionário científico & $17 \%$ & $22 \%$ & $61 \%$ & $42 \%$ & $16 \%$ & $42 \%$ \\
\hline 3. entrada secundária & $17 \%$ & $17 \%$ & $65 \%$ & 0 & $16 \%$ & $84 \%$ \\
\hline 4. verbete & $19 \%$ & $53 \%$ & $17 \%$ & $22 \%$ & $52 \%$ & $26 \%$ \\
\hline 5. definição analítica & $50 \%$ & $33 \%$ & $17 \%$ & $31 \%$ & $35 \%$ & $29 \%$ \\
\hline 6. entrada & 0 & $28 \%$ & $72 \%$ & $16 \%$ & $31 \%$ & $53 \%$ \\
\hline 7. definição sinonímica & $6 \%$ & $37 \%$ & $63 \%$ & $16 \%$ & $17 \%$ & $66 \%$ \\
\hline 8. Terminografia & 0 & $72 \%$ & $28 \%$ & $33 \%$ & $35 \%$ & $34 \%$ \\
\hline 9. nomenclatura & $17 \%$ & $33 \%$ & $50 \%$ & $17 \%$ & $33 \%$ & $50 \%$ \\
\hline 10. front matter & $35 \%$ & $35 \%$ & $30 \%$ & $61 \%$ & $28 \%$ & $11 \%$ \\
\hline
\end{tabular}

Tabela 2: Nível de compreensão conceitual por pergunta

Fonte: produzida pelas autoras

No primeiro texto e questão do questionário, o conceito solicitado era o de dicionário de língua. Observa-se que, neste caso, com uma porcentagem de $47 \%$ contra $33 \%$, foi maior o nível de compreensão efetiva nos textos em que a variante denominativa dicionário de usos foi apresentada.

1) Entenda-se dicionário de língua como aquele que dá informações sistemáticas sobre a estrutura e o funcionamento da língua. Assim também pode ser chamado de dicionário de usos.

Quanto aos textos em que as variantes foram omitidas, observa-se que a maior porcentagem se registrou no nível de compreensão parcial com 50\%. Nesta questão apresentavam-se cinco afirmativas, dentre as quais, apenas duas eram corretas. Todas as alternativas remetiam a características que definiam um tipo de obra lexicográfica, mas apenas duas delas correspondiam ao conceito de dicionário de língua. 
Assim, das cinco alternativas apresentadas, eram corretas as opções a) cuja definição era: "obra que orienta sobre a utilização de uma determinada unidade lexical"; e c), que definia o conceito como: "obra lexicográfica cujo objetivo é esclarecer dúvidas a respeito do significado e apresentar informações sobre formação, sinonímia, contexto, entre outros aspectos da palavra-entrada”. A primeira delas destacava uma característica apresentada na variante dicionário de usos e a segunda, uma característica refletida no termo de referência.

Esse resultado também foi alcançado na questão número 5, na qual se solicitava o conceito de definição analítica. Com uma porcentagem de 50\%, foi maior a quantidade de estudantes que obtiveram uma compreensão efetiva nos textos em que a variante definição aristotélica foi apresentada, sobre os $33 \%$ dos textos em que se suprimiu a variante:

2) Na definição analítica [também denominada definição aristotélica] o enunciado explicita o sentido da palavra ou expressão por meio de duas partes principais: um hiperônimo (a categoria a que a palavra pertence) e as diferenças específicas, isto é, as características próprias daquilo que está sendo definido.

Também, foi maior a porcentagem de estudantes que tiveram compreensão parcial nos textos sem variação, com 35\%.

Nesta questão, das cinco afirmativas apresentadas, duas delas retomavam o conceito de definição analítica: b) ( ) definição que consiste na decomposição e análise lógica e alternativa; e e) ( ) enunciado definitório que se embasa nos princípios da lógica aristotélica, que parte de uma categorização mais ampla ou preliminar (hiperônimo), para se chegar a um sentido mais restrito e conciso. A alternativa B ressalta uma característica apresentada no termo de referência e a alternativa E uma característica apresentada na variante definição aristotélica.

Constata-se que, nas duas questões apresentadas, a variação teve uma incidência positiva para o leitor, auxiliando na compreensão do conceito, uma vez que a variante apresentava características essenciais para a construção e representação do conceito. Traços distintivos do termo de referência, e que não puderam ser percebidos nos textos que não apresentavam variantes, o que justifica a maior porcentagem de estudantes que obtiveram uma compreensão total do conceito nos textos com variantes, em relação aos outros textos.

Verificou-se, também, que a única questão em que se obteve compreensão efetiva nos textos sem variantes ocorreu na pergunta número dez, em que se solicitava o conceito de front matter. Com uma porcentagem de $61 \%$ foi maior a quantidade de estudantes que compreenderam efetivamente o conceito nos textos sem variantes em relação aos $31 \%$ nos textos em que a variante partes introdutórias foi apresentada:

3) [...] Por fim, o front matter (ou as chamadas partes introdutórias) tem como funções básicas apresentar os objetivos que o dicionário pretende cumprir e funcionar como um manual de instruções de uso do mesmo (cf. FORNARI, 2008).

Das cinco afirmativas apresentadas nessa pergunta, apenas as alternativas a) ( ) material apresentado ao início do dicionário; e d) ( ) partes que introduzem uma obra lexicográfica, geralmente apresentadas anteriormente à macro e microestrutura, eram verdadeiras. Constata-se, nesse caso, que a variação não era fundamental para a compreensão do conceito, uma vez que a variante apenas reforçava uma característica que já estava presente no termo de referência. Sendo assim, dizemos que a variação não teve nenhuma incidência sobre o leitor e na forma como este compreendeu o conceito.

A respeito dos casos em que a compreensão foi parcial, destaca-se que esse fato teve maior ocorrência nos textos sem variantes do que nos textos em que a variante estava presente. Nos textos com variantes os estudantes alcançaram uma maior porcentagem de compreensão parcial nas questões 4, em que se solicitava o conceito de verbete com 53\% e 8, com o conceito de Terminografia com uma porcentagem de 72\%. Convém ressaltar que o mesmo ocorreu nas mesmas perguntas dos textos em que as variantes artigo lexicográfico e Lexicografia Especializada foram omitidas, com uma porcentagem de 52\% na questão 4 e 35\% na questão 8. 
Este resultado nos mostra que a variação tinha uma influência cognitiva sobre a compreensão, mas as informações apresentadas pelas variantes, assim como as informações veiculadas na superfície textual, não eram suficientes para que se alcançasse uma compreensão total e efetiva do conceito.

Em relação ao nível insuficiente de compreensão, verificou-se uma maior quantidade de perguntas em que esse resultado foi alcançado tanto nos textos com variação quanto nos textos sem variantes. É interessante observar que esse resultado ocorreu nas mesmas questões dos dois modelos de textos. Assim, na questão 2 em que se solicitava o conceito de dicionário científico, obtevese uma porcentagem de $61 \%$ nos textos com variantes e $42 \%$ nos textos em que a variante dicionário técnico foi suprimida:

4) [...] Finalmente vou considerar os dicionários especialmente dedicados a um domínio do conhecimento, que não a linguagem. São dicionários científicos e/ou técnicos.

O mesmo ocorreu na questão 3, em que se veiculava o conceito de entrada secundária, com 65\% nos textos com variantes e $84 \%$ nos textos em que a variante subentrada foi omitida. "[...] Uma vez encerrada a série de acepções, aparecem, quando é o caso, as entradas secundárias ou subentradas, que podem se constituir tanto de palavras derivadas da entrada principal [...]".

Na questão 6, na qual se apresentava o conceito de entrada, tivemos uma porcentagem de $72 \%$ nos textos com variantes e $53 \%$ nos textos sem as variantes denominativas:

5) A entrada [o mesmo que lema, cabeça de verbete, palavra-entrada] é a palavra ou expressão que encabeça o verbete, o elemento a ser definido ou explicado.

Foi grande a porcentagem no nível de compreensão insuficiente na questão 7, na qual se solicitava o conceito de definição sinonímica. Nesta questão, obteve-se a porcentagem de $63 \%$ nos textos com variantes e $66 \%$ nos textos sem a variante denominativa pseudodefinição:

6) [...] A definição sinonímica [também denominada pseudodefinição] é um procedimento de explicação do sentido de uma palavra ou expressão em que não há propriamente um enunciado definitório [...].

Na questão 9, na qual se apresentava o conceito de nomenclatura, verificou-se um consenso de 50\% nos textos com variantes e $50 \%$ nos textos sem a variante denominativa macroestrutura: "[...] Para organizar esse acervo lexical, o primeiro passo será definir $\underline{\text { a }}$ nomenclatura ou macroestrutura da obra [...]".

Em todas as questões se apresentavam cinco afirmativas que remetiam ao conceito, mas apenas duas ou três delas eram verdadeiras, sendo que uma das alternativas apresentava uma informação veiculada pelo termo de referência e outra que ressaltava uma característica apresentada na variante, como podemos observar na questão número 9, em que das cinco afirmativas apresentadas, eram verdadeiras as afirmativas (a), (c) e (e).

a) ( ) relação das palavras que serão definidas em um dicionário.

b) ( ) arranjo do artigo lexicográfico que consiste na entrada e sua definição.

c) ( ) estruturação maior que compreende as unidades lematizadas em uma obra lexicográfica.

d) ( ) seleção de nomes, quase sempre verbos, que compõem um verbete.

e) ( ) organização ou arranjo das entradas seguindo, na maioria das vezes, uma ordenação alfabética e semasiológica.

Como apontamos anteriormente, ao delinearmos esta investigação consideramos como uma das hipóteses o fato de que se fosse maior a porcentagem de compreensão insuficiente nos textos com variação, significava que a variação teria uma incidência negativa para o leitor, dificultando a compreensão do conceito. Entretanto, depois de analisar os dados, principalmente em relação às últimas perguntas apresentadas, constatamos que esse questionário não nos permitiu comprovar essa hipótese, mesmo porque o resultado obtido nos mostra que o problema ou dificuldade na compreensão conceitual não estava no uso ou não de variantes, e 
sim, na influência de fatores externos como o alto grau de complexidade dos textos para o nível de conhecimento dos participantes, termos muito especializados e conceitos muito difíceis e abstratos para os estudantes, como é o caso do conceito de Terminografia, e quantidade insuficiente de informações na superfície textual que pudessem auxiliar na compreensão.

\section{CONSIDERAÇÕES FINAIS}

Neste trabalho, tivemos por objetivo analisar a incidência da variação na compreensão do conceito especializado dos termos da Lexicografia brasileira. Para isso, procedemos a uma análise de questionários aplicados a estudantes universitários de uma universidade pública do Brasil.

Partimos da hipótese principal de que a variação apresentava uma incidência positiva sobre o leitor, uma vez que auxiliava na compreensão do conceito. Para comprovar essa hipótese, selecionamos dez textos com e sem variantes denominativas, nos quais se apresentava uma pergunta a respeito do conceito veiculado no fragmento, tendo, cada questão, cinco afirmativas que remetiam ao conceito, nas quais apenas duas ou três delas eram verdadeiras. Por meio das respostas obtidas nessas perguntas estabelecemos uma escala de pontuação que nos permitiu analisar o nível de compreensão conceitual e, assim, comprovar se a compreensão foi efetiva, parcial ou insuficiente.

A princípio acreditávamos que nossa análise nos permitiria comprovar a incidência da variação para o leitor, sendo esta positiva, nos casos em que fosse maior o nível de compreensão efetiva nos textos com variantes e, negativa, nos casos em que fosse maior o número de compreensão insuficiente nos textos sem variantes. Entretanto, nossa análise não nos permitiu comprovar totalmente essas hipóteses.

Por meio de nossa análise, pudemos constatar que, em alguns casos, a variação desempenhou um papel importante para a compreensão do conceito, tendo nesse caso uma incidência positiva. Isto pôde ser comprovado nas questões 1 e 5 em que obtevese uma porcentagem de $47 \%$ nos textos com variantes, e apenas $33 \%$ nos textos sem variantes.

Em outros casos, a variação não apresentava nenhuma interferência na compreensão do conceito, de forma que foi maior a quantidade de estudantes com compreensão efetiva nas questões em que a variante foi suprimida. Como é o caso da questão número 10, com uma porcentagem de $61 \%$ nos textos sem variação contra 35\% nos textos em que a variante foi apresentada. Nestes casos, a variante apenas reforçava uma informação que já se apresentava no termo de referência e na superfície textual e, portanto, a variação não interferiu na compreensão do conceito.

Por outro lado, observamos que na maioria das questões a compreensão foi insuficiente, tanto nos textos com ou sem variantes. Isso se pôde constatar nas questões 2, 3, 6, 7 e 9. Entretanto, este resultado não nos permitiu comprovar com certeza se a incidência da variação foi negativa nesses casos, mesmo porque foi ínfima a diferença de compreensão entre os textos com ou sem variantes nestas questões. Sendo assim, acreditamos que o principal problema consiste em fatores externos ao fenômeno da variação, tais como: i) a má seleção dos textos, muito difíceis para os participantes; ii) elaboração das perguntas; iii) ausência de conhecimento prévio por parte dos alunos, que a princípio acreditamos que fosse o ideal, mas que vimos que, posteriormente, se converteu em um obstáculo; iv) insuficiência de informações representadas nos textos e nas variantes; ou mesmo v) a falta de prática de se trabalhar com textos em sala de aula. Neste sentido, constatamos que mais que um problema de incidência da variação, temos um problema de inadequação de questionário e público-alvo.

Convém ressaltar que esse resultado nos permitiu reconhecer e ressaltar as debilidades do nosso trabalho, uma vez que concluímos que a compreensão insuficiente desses textos e conceitos não estava relacionada apenas à presença ou ausência de variação e, portanto, estes aspectos devem ser considerados e sanados em um trabalho futuro, principalmente na seleção de participantes de um nível escolar mais avançado e textos menos complexos, que nos permitam evidenciar realmente a incidência da variação. 


\section{REFERENCIAS}

BOWKER, L.; HAWKINS, S. Variation in the organisation of medical terms: Exploring some motivations for term choice. Terminology, v.12, n.1, p. 79-110, 2006.

CABRÉ, M. T. La Terminología: representación y comunicación: elementos para una teoria de base comunicativa y otros artículos. Girona: Documenta Universitaria, 1999.

CABRÉ, M. T. El principio de poliedricidad: la articulación de lo discursivo, lo cognitivo y lo lingüístico em Terminología. Ibérica, v. 16, p. 9-36, 2008.

CIAPÚSCIO., G. Textos especializados y terminología. Barcelona: IULA-UPF, 2003.

COSTA, L. A. C. Reflexões sobre a variação terminológica na lexicografia corrente no Brasil e a construção das bases teóricometodológicas para o dicionário de Lexicografia brasileira. 2015. Tese (Doutorado) - Universidade Estadual Paulista, São José do Rio Preto; Universidad Pompeu Fabra, Barcelona, 2015.

COSTA, L. A. C.; FERNÁNDEZ-SILVA, S. Análisis de la función cognitiva de la variación denominativa en la Lexicografía brasileña: patrones conceptuales de variación y distancia semántica entre las variantes. Revista Meta, v.63., n.2, p.467-491, 2018.

FABER, P. et al. A cognitive linguistics view of terminology and specialized language. Berlin, Boston: Mouton de Gruyter, 2012.

FABER, P. et al. Process-oriented terminology management in the domain of Coastal Engineering. Terminology, v.12, n.1, p. 189213, 2006.

FÉREZ, P. C. La semántica conceptual. In: IBARRETXE-ANTUÑANO, I.; VALENZUELA, J. (ed.). Lingüística cognitiva. Barcelona: Anthropos, 2012.

FERNÁNDEZ-SILVA, S. Variación terminológica y cognición: factores cognitivos en la denominación del concepto especializado. Barcelona: IULA-TDX, 2011.

FERNÁNDEZ- SILVA, S. The cognitive and rhetorical role of term variation and its contribution to knowledge construction in research articles. Terminology, v.22, n.1, p. 52-79, 2016.

FERNÁNDEZ-SILVA, S; FREIXA, J; CABRÉ, M. T. A proposed method for analysing the dynamics of cognition through term variation. Terminology, v.17, n.1, p. 49-74, 2011.

FERNÁNDEZ-SILVA, S. et al. A cognitive approach to synonymy in terminology. In: M. BRDAR, M.; RAFFAELLI, I; FUCHS, M. Žic (ed.). Cognitive linguistics between universality and variation. Newcastle: Cambridge Scholars Publishing, p.189-212, 2012.

FERNÁNDEZ-SILVA, S; BECERRA, N. La variación terminológica en la comprensión y producción de textos académicos: propuesta de representación en un diccionario especializado de aprendizaje de Psicología. Iberica, v.30, p.183-208, 2015.

FILLMORE, C. Frames and the semantics of understanding. Quaderni di semantica, v.6, n.2, p. 222-254, 1985.

FREIXA, J. La variació rerminologica: Anàlisi de la variació denominativa en textos de diferent grau d'especialització de l'àrea de medi ambient. Barcelona: IULA, 2002. 
IBARRETXE-ANTUÑANO, I.; VALENZUELA, J. Lingüistica cognitiva. Barcelona: Anthropos, 2012.

KAGEURA, K. The dynamics of terminology: a descriptive theory of term formation and terminological growth. Amsterdam/Philadelphia: John Benjamins, 2002.

PARODI, G. Comprensión de textos escritos. La Teoría de la Comunicabilidad. Buenos Aires: Eudeba, 2014.

PECMAN, M. Variation as a cognitive device: how scientists construct knowledge through term formation. Terminology, v.20, n.1, p. 1-24, 2014.

ROGERS, M. Multidimensionality in concepts systems: A bilingual textual perspective. Terminology, v.10, n.2, p. 215-240, 2004.

SUÁREZ, M. Influencia de la variación denominativa explícita (vde) en la comprensión del concepto: evidencia con la técnica de movimiento ocular (eye-tracking). In: SIMPÓSIO DA REDE IBERO-AMERICANA DE TERMINOLOGIA, 15., 2012. Anais, São Paulo: FFLCH, 2016. p.92-93

TEMMERMAN, R. Toward new ways of Terminology description: The Sociocognitive Approch. Amsterdam: John Benjamins, 2000 .

TERCEDOR, M. The Cognitive dynamics of terminological variation. Terminology, v.17, n.2, p.181-97, 2011.

\section{(ㄷ) (1) $\circledast$}

